\title{
Extraction of phospholipids from a dairy by-product (whey protein phospholipid concentrate) using ethanol
}

\author{
Nathan Price, ${ }^{*}$ Tao Fei, ${ }^{*}$ Stephanie Clark, ${ }^{*} \dagger$ and Tong Wang ${ }^{*}{ }^{1}$ \\ *Department of Food Science and Human Nutrition, and \\ †Center for Crops Utilization Research, 2312 Food Science Building, lowa State University, Ames 50011-1061
}

\begin{abstract}
There has been a great interest in the phospholipids (PL) found in dairy products because of their health and functional properties. In this study, a technology that was originally developed for egg yolk PL extraction was applied to whey protein phospholipid concentrate (WPPC). This method successfully precipitated the proteins present in WPPC and extracted the lipids with a renewable alcoholic solvent, ethanol. The effect of ethanol concentration, extraction temperature, and extraction number on the recovery of total lipid, total PL, and individual PL class was evaluated. The optimum processing conditions for a combined 5-stage sequential extraction for producing a PL-enriched lipid fraction were determined to be $70 \%$ ethanol at $70^{\circ} \mathrm{C}$, and the total lipid recovery, total PL recovery, and PL content achieved were 40.7, 58.1, and 45.8\%, respectively. A lipid fraction with high nutritional value (high content of sphingomyelin or phosphatidylserine) can also be obtained by adjusting extraction conditions and collecting specific fractions, although the yield may decrease. Overall, producing a PL-rich lipid fraction from WPPC using ethanol extraction is feasible and scalable, and different processing conditions can be used depending on the type of lipid product desired. Key words: dairy lipids, ${ }^{31} \mathrm{P}$ nuclear magnetic resonance, sphingomyelin, lecithin
\end{abstract}

\section{INTRODUCTION}

Phospholipids (PL), generally referred to as lecithin in the food industry, are a complex class of polar lipids. Phospholipids are amphiphilic because they have a hydrophilic head and hydrophobic fatty acid tail (Donato et al., 2011; Contarini and Povolo, 2013); this gives them excellent emulsification properties and makes them important functional ingredients for the food,

Received April 19, 2018.

Accepted June 15, 2018.

${ }^{1}$ Corresponding author: tongwang@iastate.edu pharmaceutical, and cosmetic industries. Other than the technological functionalities such as emulsifying and lubricating, PL have gained considerable interest because of their nutritional value. Although dairy PL represent only 0.5 to $1.0 \%$ of total milk lipids, they are of particular interest because of their higher content of sphingomyelin (SM; 4.1-29.2\% of total PL) and phosphatidylserine (PS; $2.0-16.1 \%$ of total PL) compared with other lecithin sources such as soybean and egg yolk (Burling and Graverholt, 2008; Contarini and Povolo, 2013). Sphingomyelin is reported to play important roles in cell regulation and is referred to as a tumor suppressor (Rombaut et al., 2006; Dewettinck et al., 2008; Contarini and Povolo, 2013). Cognitive performance improvement, which is of particular significance to Alzheimer's disease treatment, has been attributed to PS (Pepeu et al., 1996; Rombaut and Dewettinck, 2006; Burling and Graverholt, 2008; Dewettinck et al., 2008; Contarini and Povolo, 2013). Other beneficial biological effects such as reduced cholesterol absorption, antioxidant properties, stress and depression tolerance, reduced incidence of cardiovascular disease, and suppression of multiple sclerosis are also associated with dairy PL (Rombaut and Dewettinck, 2006; Dewettinck et al., 2008; Contarini and Povolo, 2013). Unlike soy lecithin, which lacks SM (Nejrup et al., 2017), dairy PL have greater potential to be used in infant formula for mimicking human breast milk, which contains SM and PS (Sala-Vila et al., 2005). Using dairy PL can improve the overall nutritional quality of infant formula as well as the economics of the dairy processing industry.

The majority of the current commercial lecithins are made from soybean and egg yolk. The low PL content in dairy products makes it difficult to extract and concentrate PL on an industrial scale. Commercial dairy PL concentrates are available that are produced by using technologies such as enzymatic hydrolysis of proteins, microfiltration, ultrafiltration, supercritical fluid extraction, or a combination of these technologies (Folch et al., 1957; Astaire et al., 2003; Rombaut et al., 2007; Spence et al., 2009; Costa et al., 2010; Barry et al., 2017). However, these dairy PL concentrates are 
not isolated lipid fractions, and this may limit their application as an industrial lecithin. The commercial dairy product with the highest PL content, Phospholipid Concentrate 700 (Fonterra Co-Operative Group Ltd., Auckland, New Zealand), contains up to $60 \%$ (wt/ wt) PL (Fong et al., 2013). The processing steps that this product undergoes are an industrial trade secret. This product contains a substantially higher amount of PL than any other product reported in the literature. Previously, the highest PL content reported in a dairy product was $23.7 \%$ on a dry basis, concentrated from butter serum using microfiltration (Le et al., 2011). The major limiting factor with microfiltration of buttermilk and butter serum is the retention of casein, which limits how concentrated the PL can become. Developing processing technologies that can be used to produce PL-rich products is a top priority for the dairy industry. Moreover, certain feedstock and technologies used for producing the PL concentrates are not always cost effective, and this leads to low feasibility for commercial-scale production. Therefore, there is a need to develop a more cost-effective, readily scalable extraction method to produce a high-purity dairy PL fraction from an economical source other than buttermilk and butter serum.

Whey protein PL concentrate (WPPC) is a byproduct that is microfiltered from cheese whey during the production of whey protein isolate. Whey protein PL concentrate contains 60 to $70 \%$ whey protein, and 10 to $30 \%$ of the total lipid content is PL ( $\mathrm{Li}$ et al., 2016). It is a highly underused product and would be a great feedstock for dairy PL concentration. A method that can be used for producing WPPC lipid with high PL content is the simultaneous texturization and extraction of PL (STEP) method, which was originally developed to extract PL from liquid egg yolk using ethanol (Wang et al., 2017). The principles in the STEP method may be applied to WPPC for PL concentration, but modifications are needed because the composition of egg yolk and WPPC is very different.

The use of ethanol to extract PL from WPPC was investigated. We hypothesized that (1) lower ethanol concentration can lead to a higher PL content in the final product, whereas higher ethanol concentration can lead to higher recovery yield of total lipids and PL due to the different affinities of lipids to solvent with different polarity, and (2) higher extraction temperatures can result in higher PL content as well as higher recovery of total lipids and PL due to a more complete denaturation of protein and better lipid solubilization in ethanol. To test these hypotheses, different ethanol concentrations and temperature conditions were used for the extraction, and total lipid and PL recovered from WPPC were quantified. Each individual PL class composition was also quantified to evaluate the effect of ethanol concentration and temperature on recovery of each specific class of PL.

\section{MATERIALS AND METHODS}

The WPPC used in this study was provided by Bongards' Creameries (Perham, MN). The WPPC was frozen $\left(-20^{\circ} \mathrm{C}\right)$ before treatment to guarantee a consistent product quality for each replicate extraction. The extracted lipid was then quantified for PL using ${ }^{31} \mathrm{P}$ nuclear magnetic resonance (NMR; Wang et al., 2014). Reagent-grade solvents and other chemicals were purchased from Fisher Scientific (Fair Lawn, NJ) and Sigma-Aldrich (St. Louis, MO).

\section{Extraction of PL from WPPC}

The extraction procedure, which has similar extraction principles as the STEP method (Wang et al., 2016, 2017), was performed using WPPC as a feedstock. A laboratory extraction system (Figure 1) designed for the STEP method on egg yolk was adapted to extract total lipid and PL from WPPC. Aqueous ethanol with final concentrations of 70,80 , and $90 \%$ was used, and the temperature of the solvent in the solvent reservoir and extraction cylinder was maintained at 60,70 , and $80^{\circ} \mathrm{C}$ using a hot water jacket heating system (Haake DC 10, Thermo Haake, Karlsruhe, Germany). Liquid WPPC, in the form of a thin stream, was injected using an 18-guage $\times 1.5$-inch PrecisionGlide needle (Becton Dickinson and Co., Franklin Lakes, NJ) into the hot solvent, and the protein in WPPC was denatured and solidified into short strings upon contact with ethanol. The liquid WPPC was heated to $60^{\circ} \mathrm{C}$ before injection to make the product more flowable, and it was metered using a peristaltic flow pump (UL 3101-1, Wheaton Science Products, Waltham, MA) at a speed of $0.67 \mathrm{~g} / \mathrm{min}$ through the syringe needle. The needle was manually rotated in a circular motion below the surface of the solvent to obtain uniform protein denaturation and to produce a thin-diameter WPPC string. Liquid WPPC $(100 \mathrm{~g})$ was spun into various amounts of ethanol depending on ethanol concentration; 187, 320, and 720 $\mathrm{mL}$ of $100 \%$ ethanol were used for 70,80 , and $90 \%$ ethanol concentration treatment. After protein denaturation, WPPC was immersed in the solvent for $6 \mathrm{~min}$ before drainage of the miscella for $1 \mathrm{~min}$. The first extraction was considered complete after the miscella was collected; then, 4 subsequent extractions were carried out on the partially delipidated WPPC using the same conditions, except only $100 \mathrm{~mL}$ of the ethanol solvent was used. For the first extraction, the ethanol solvent concentration was $100 \%$ so that the concentration of 
the mixture would be 70,80 , or $90 \%$ after WPPC was injected (taking the moisture content of WPPC into consideration). For all subsequent extractions, prepared solvent solutions with 70,80 , and $90 \%$ ethanol were used. Overall, 5 samples of miscella were produced and collected. The solvent in each miscella was removed by a rotary evaporator, and the lipids were further dried in a vacuum oven at $40^{\circ} \mathrm{C}$ overnight before weighing.

Total lipid in WPPC extracted using the Folch method (Rodríguez-Alcalá and Fontecha, 2010) was used as a control. The lipid was extracted using 2:1 (vol/vol) chloroform:methanol, and PL composition of the lipid was analyzed using the method reported in the following section.

\section{Quantification of PL}

The PL content and the class composition were determined using ${ }^{31} \mathrm{P}$ NMR following a method reported by Wang et al. (2014) with minor modifications. About $0.2 \mathrm{~g}$ of lipid extracted from WPPC was dissolved in $12 \mathrm{~mL}$ of $2: 1$ (vol/vol) chloroform:methanol and then washed with $3 \mathrm{~mL}$ of K-EDTA $(0.1 \mathrm{M}, \mathrm{pH}$ 7.0). The denser chloroform phase, which contains the lipid, was collected, and the residual water was removed using $0.5 \mathrm{~g}$ of anhydrous sodium sulfate. Then, the solution was filtered through a $0.45-\mu \mathrm{m}$ polytetrafluoroethylene filter disc and dried using a rotary evaporator. About $200 \mathrm{mg}$ of the dried lipids was dissolved in $1 \mathrm{~mL}$ of chloroform- $d$ and $1 \mathrm{~mL}$ of methanol with the addition of 100 to $150 \mathrm{mg}$ of triphenyl phosphate as an internal standard. One milliliter of Cs-EDTA (0.2 M, pH 8.5) was added to the sample solution, and the mixture was centrifuged at $1,800 \times g$ for 2 min after $10 \mathrm{~s}$ of vigorous mixing. The denser chloroform- $d$ phase was then collected into NMR tubes and subjected to ${ }^{31} \mathrm{P}$ NMR analysis. The NMR spectra were obtained with a Bruker Avance III NMR spectrometer (Billerica, MA) using a Bruker narrow bore 14.1 tesla superconducting magnet operating at $162 \mathrm{MHz}$. Samples were analyzed with an inverse gated decoupling pulse sequence. The NMR spectroscopic scan conditions were as follows: probe temperature of $30^{\circ} \mathrm{C}$, pulse width of $22 \mu \mathrm{s}$, sweep width of $9,718 \mathrm{~Hz}$, acquisition time of $1.2 \mathrm{~s}$, relaxation delay of $10 \mathrm{~s}$, and a total of 384 scans. The chemical shifts were recorded relative to triphenyl phosphate $(\delta$ $-17.8)$. The relative composition percentage was expressed in molar percentage relative to the sum of all PL classes.

\section{Statistical Analysis}

All temperature and alcohol concentration treatments were randomized in the order of extraction, with

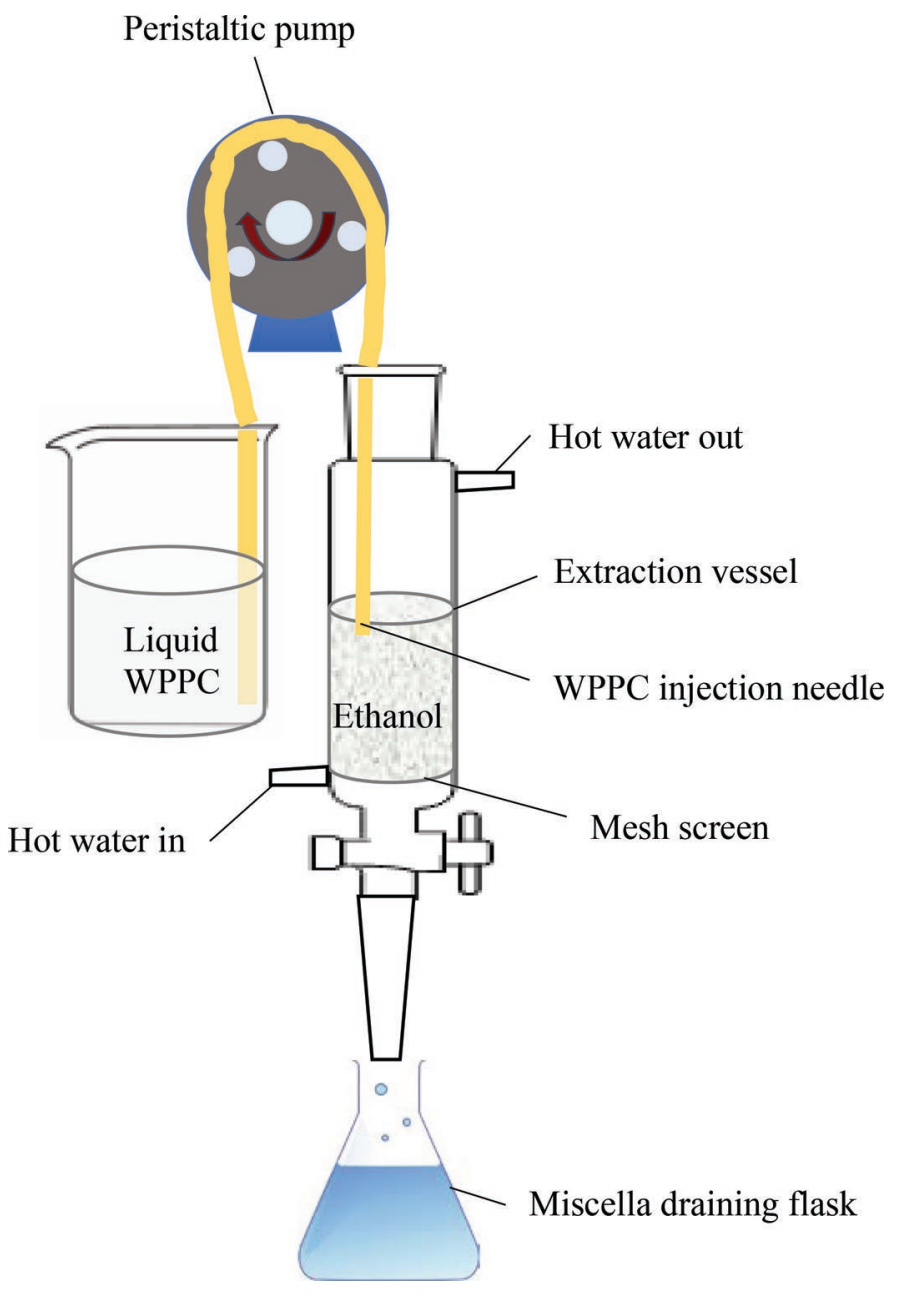

Figure 1. Solvent extraction system used for extraction of phospholipids from whey protein phospholipid concentrate (WPPC). Color version available online.

2 replicates for each treatment. Data collected were analyzed using SAS 9.1 (SAS Institute Inc., Cary, NC), and a Tukey test was used to determine significant differences at $P=0.05$. The relative average deviation from the mean for all treatments was calculated and presented as the error bar on the charts.

\section{RESULTS AND DISCUSSION}

\section{WPPC Composition}

The composition of the initial liquid WPPC used for the extraction is shown in Table 1. It contained $20.2 \%$ TS, with a total lipid content of $5.5 \%(27.0 \%$ on a dry basis), and a PL content of $1.6 \%$ (29.1\% on a fat basis). The protein content of WPPC is approximately $65 \%$ on a dry basis, which equates to $13.1 \%$ as is, with the remainder of the product being ash. Because WPPC 
Table 1. Phospholipid (PL) class distribution of the liquid whey protein phospholipid concentrate (WPPC) compared with other studies on whey protein concentrate powder and milk fat ${ }^{1}$

\begin{tabular}{lcccccc}
\hline Item & SM & PE & PS & PI & PC & PL (\% of total fat) \\
\hline WPPC & $7.9 \pm 0.1$ & $47.8 \pm 1.4$ & $8.2 \pm 0.1$ & $5.1 \pm 0.2$ & $31.0 \pm 0.7$ & $29.1 \pm 0.7$ \\
Whey powder $^{2}$ & 3.9 & 36.0 & 32.6 & 5.3 & $8.9(\mathrm{PS}+\mathrm{PI})$ & 51.2 \\
Milk $^{3}$ & 21.3 & 7.6 & 33.2 & $0.5-1.0$ \\
\hline
\end{tabular}

${ }^{1} \mathrm{SM}=$ sphingomyelin; $\mathrm{PE}=$ phosphatidylethanolamine; PS = phosphatidylserine; $\mathrm{PI}=$ phosphatidylinositol; PC = phosphatidylcholine.

${ }^{2}$ Results from Boyd et al. (1999); PS and PI results were quantified together.

${ }^{3}$ Results from Fong et al. (2007) on milk fat.

contains such a high amount of protein, the denaturation of the protein is vital for the success of the PL extraction. The effective precipitation of the protein and dissolution of PL during the extraction are necessary.

The major PL classes in the initial liquid WPPC (Table 1), characterized by ${ }^{31} \mathrm{P}$ NMR, were phosphatidylethanolamine (PE; $47.8 \%$ of the total PL) and phosphatidylcholine (PC; $31.0 \%$ of the total PL). Lower amounts of PS, SM, and phosphatidylinositol (PI) were measured at $8.2,7.9$, and $5.1 \%$ of the total PL in WPPC, respectively. Similar results were found by other researchers for WPPC and whey-based powders (Boyd, et al., 1999; Levin et al., 2016), with PE and PC being the most abundant PL classes. Because WPPC has a relatively low content of SM and PS, it is important for the extraction process to have a high affinity for these PL classes so that the final product can have the highest possible concentration of PL in the final product as well as enriched SM and PS.

\section{Effect of Extraction Temperature and Ethanol Concentration on Lipid Recovery}

Total Lipid Recovery. The total lipid recovery was calculated by adding all 5 sequential extractions together to obtain a complete recovery for each treatment (Figure 2). The yield of each extraction was calculated based on the total lipid present quantified by the Folch extraction. The Folch extraction yielded 5.5\% total lipid, which equates to $5.5 \mathrm{~g}$ of lipid for each 100 $\mathrm{g}$ of WPPC injected into the extraction system. This extraction resulted in a complete lipid recovery, and a $100 \%$ yield was based on recovering $5.5 \mathrm{~g}$ of lipid from the initial WPPC.

The effect of extraction temperature on total lipid recovery was examined, and results are shown in Figure 2. Temperature was a significant factor in the recovery of total lipid $(P<0.05)$. Total lipid recovery increased as the extraction temperature increased. Increasing the temperature from 60 to $70^{\circ} \mathrm{C}$ and 60 to $80^{\circ} \mathrm{C}$ significantly increased the total lipid recovery $(P<0.05)$. However, increasing the temperature from 70 to $80^{\circ} \mathrm{C}$ did not significantly affect total lipid recovery $(P>$
0.05); as shown, a plateau or even a slight decrease in total lipid recovery was evident when the 70 and $80 \%$ ethanol concentrations were compared. This is due to temperatures above $70^{\circ} \mathrm{C}$ not being as effective at further increasing the degree of protein denaturation. The denaturation temperature of milk whey proteins is near $70^{\circ} \mathrm{C}$ (Walstra et al., 2006). Overall, it was determined that the optimum temperature for protein denaturation is $70^{\circ} \mathrm{C}$ for WPPC, and total lipid recovery values were $40.7,56.3$, and $93.8 \%$ at 70,80 , and $90 \%$ ethanol concentrations, respectively.

The effect of ethanol concentration on total lipid recovery was also examined. There was a significant increase in total lipid recovery as the ethanol concentration increased $(P<0.05$; Figure 2$)$. It was observed that $90 \%$ ethanol concentration resulted in the highest total lipid recovery for all of the temperature treatments, and a total lipid recovery of $101.7 \%$ was achieved at $80^{\circ} \mathrm{C}$. The higher total lipid recovery with increasing ethanol concentrations is probably due to a higher degree of protein denaturation along with increased lipid solubilization in higher concentration of ethanol. Another factor that may have contributed to the nearcomplete extraction with $90 \%$ ethanol is that for the first extraction a different quantity of $100 \%$ ethanol

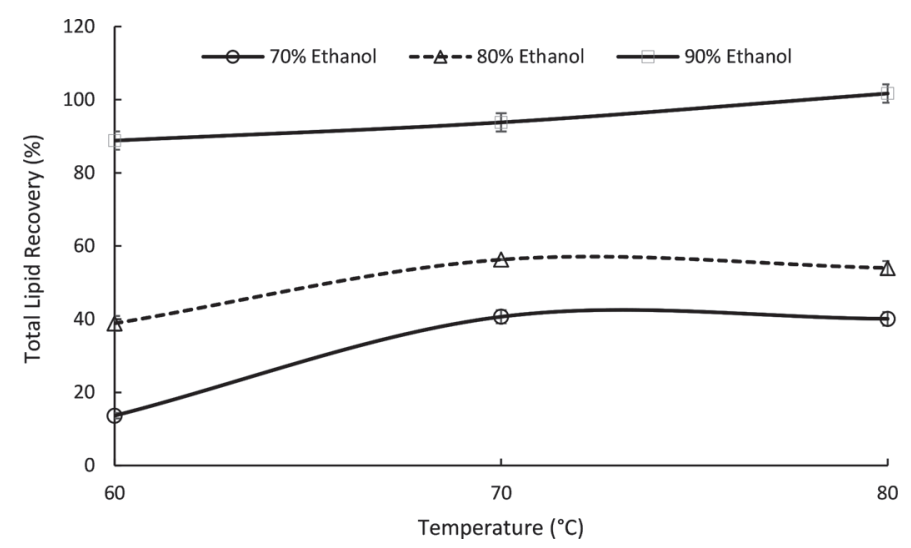

Figure 2. The effect of extraction temperature and ethanol concentration on total lipid recovery from whey protein phospholipid concentrate. Error bars are relative average SD from the mean. 
had to be used to achieve the concentration desired. Therefore, the solvent and WPPC ratios were 1.9, 3.2, and 7.2 for the 70,80 , and $90 \%$ ethanol treatments, respectively. The higher amount of ethanol used at $90 \%$ treatment may have led to a better separation of lipid from protein in the denatured WPPC protein.

Total PL Recovery. The total PL recovery was calculated by adding all 5 sequential extractions of PL to obtain a complete recovery for each treatment (Figure 3 ). The yield of each extraction was calculated based on the total PL content quantified by the Folch extraction. The Folch extraction yielded $1.6 \%$ total PL, which equates to $1.6 \mathrm{~g}$ of PL for each $100 \mathrm{~g}$ of WPPC $(29.1 \%$ PL of total lipid fraction) injected into the extractor.

The PL recovery displayed a trend similar to that of total lipid, where higher total PL recoveries were obtained at higher ethanol concentrations and temperatures (Figure 3). The temperature of the extraction had a significant effect on the total PL recovery $(P<$ 0.05). Increasing the temperature from 60 to $70^{\circ} \mathrm{C}$ led to a significant increase in total PL recovery for all 3 ethanol concentrations $(P<0.05)$, whereas increasing the temperature from 70 to $80^{\circ} \mathrm{C}$ led to no change $(70$ and $90 \%$ ethanol) or a decrease in total PL recovery ( $80 \%$ ethanol). The reduction may be due to the high degree of protein denaturation and the entrapment of PL in the protein matrix. Because of the higher amount of solvent used for the $90 \%$ ethanol treatment, this reduction was not as obvious. These results were similar to the recoveries of total lipid. Overall, the $70^{\circ} \mathrm{C}$ treatment resulted in the highest PL recovery, and the values were $58.1,75.4$, and $100.8 \%$ at 70,80 , and $90 \%$ ethanol concentration, respectively.

The concentration of ethanol was a significant factor for total PL recovery $(P<0.05)$. The total PL recovery increased as the ethanol concentration increased. A similar effect of ethanol concentration on PL recovery was also reported by Wang et al. (2017). Overall, for the most complete recovery of PL, the optimal ethanol concentration for total PL recovery was determined to be $90 \%$ ethanol at $70^{\circ} \mathrm{C}$ if not considering the $\mathrm{PL}$ content in the final lipid extract.

\section{Effect of Ethanol Concentration and Temperature on the Efficiency of Lipid Recovery}

Total Lipid Recovery Profile. A total of 5 sequential extractions were completed to simulate industrial multiple-stage extraction and determine the speed of lipid depletion from the WPPC. The amount of total lipid recovered by each extraction was quantified to determine the extraction efficiency or speed. Figure 4a through $\mathrm{c}$ indicate that the first extraction always resulted in significantly more total lipid recovery than the

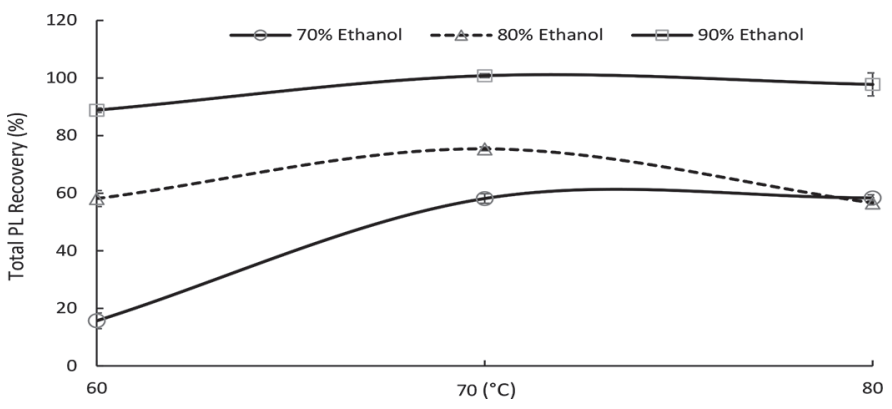

Figure 3. The effect of extraction temperature and ethanol concentration on total phospholipid recovery from whey protein phospholipid concentrate. Error bars are relative average SD from the mean.

other extractions $(P<0.05)$. The majority of the lipids were recovered with the first 2 extractions, and there was no significant increase in the amount of total lipid recovered in extractions 3,4 , and $5(P>0.05)$. Figure 4a through c also shows that $90 \%$ ethanol resulted in higher total lipid recovery efficiency than 70 and $80 \%$ ethanol, whereas the $80^{\circ} \mathrm{C}$ temperature treatment resulted in the highest total lipid recovery, with $73.2 \%$ of the total lipid being recovered during the first extraction. It can also be observed that for all the temperature treatments, less total lipid was recovered during the first extraction as the ethanol concentration and temperature decreased. It was expected that the first extraction would result in the most total lipid recovery because the majority of the protein denaturation and lipid solubilization occurs during this extraction. Figure 4 a shows that the $70 \%$ ethanol at $60^{\circ} \mathrm{C}$ treatment resulted in the lowest total lipid recovery $(5.4 \%)$ for the first extraction and that the total lipid recovery was significantly increased when the temperature increased above $60^{\circ} \mathrm{C}$. This is most likely due to poor protein denaturation at $60^{\circ} \mathrm{C}$, whereas increasing the temperature significantly improved protein denaturation and lipid solubility. Overall, statistical analysis showed that both temperature and ethanol concentration were significant factors for the total lipid extraction efficiency or speed of the process $(P<0.05)$.

Total PL Recovery Profile and PL Content in the Product. The efficiency of the PL recovery is shown in Figure 5a through c and Table 2. A trend similar to that of total lipid extraction was observed. However, as the ethanol concentration increased from 70 to $90 \%$, the content of PL in each of the lipid fractions decreased in general (Table 2), although total PL recovery increased. This indicates that lower ethanol concentrations have a stronger affinity for PL, whereas higher ethanol concentration extracted more total lipid. The treatment that resulted in the highest PL content in the lipid fraction for all 5 extractions was the 


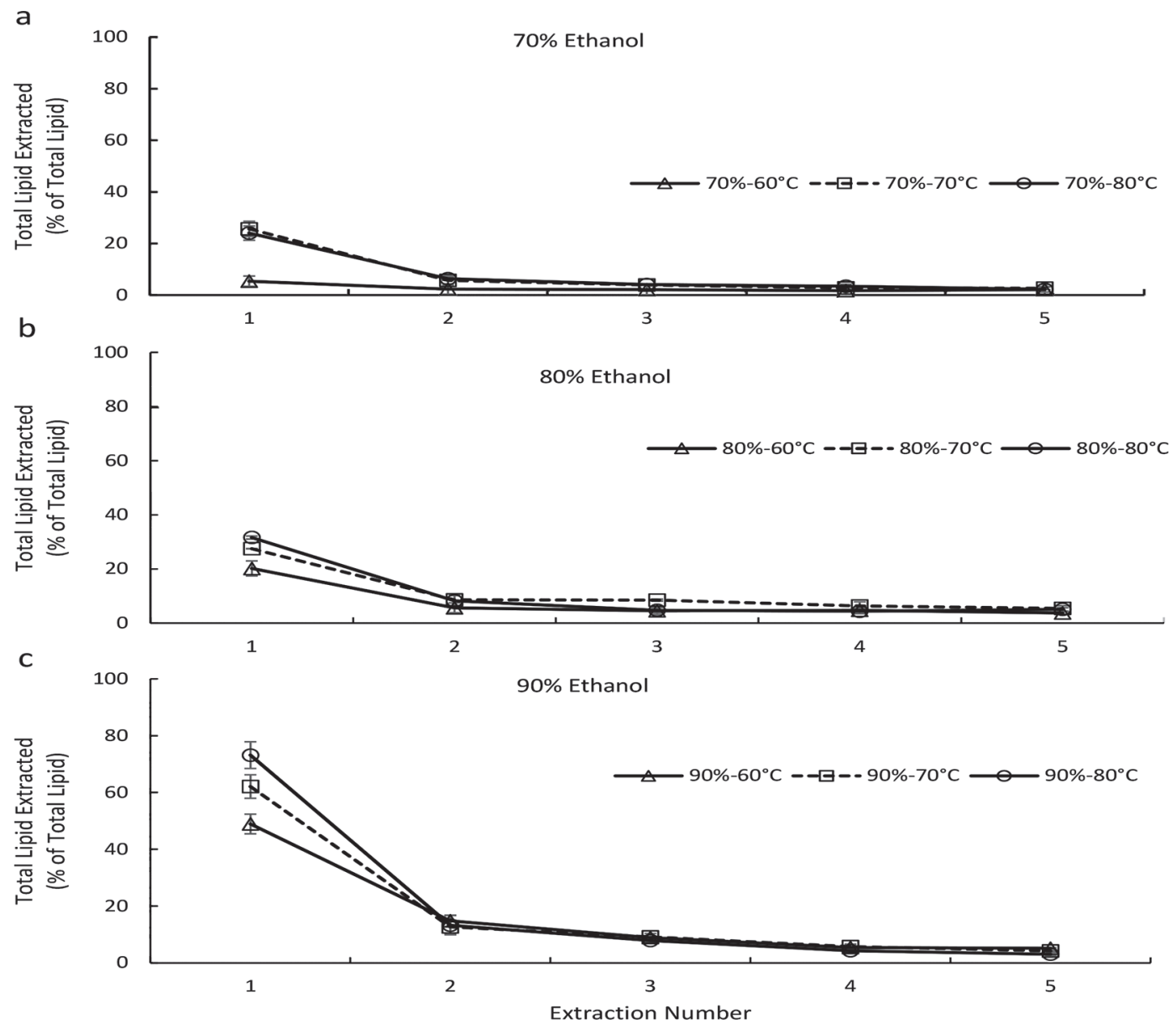

Figure 4. Effect of extraction number, temperature, and ethanol concentration on total lipid recovery. Error bars are relative average SD from the mean.

$70 \%$ ethanol at $70^{\circ} \mathrm{C}$ treatment $(36.8-65.6 \% \mathrm{PL})$. The optimum temperature for PL recovery from WPPC was $70^{\circ} \mathrm{C}$, and it was observed that $60^{\circ} \mathrm{C}$ had a slight advantage for $\mathrm{PL}$ content in general compared with $80^{\circ} \mathrm{C}$. This is because the higher temperatures resulted in a significantly higher neutral lipid recovery, which relatively lowered the proportion of PL in the final lipid fraction.

The first extraction always resulted in significantly more PL recovery than the other extractions $(P<$ $0.05)$. The majority of the PL were recovered with the first 2 extractions, and there was no significant increase in the amount of PL recovery in extractions 3,4 , and 5 $(P>0.05)$. All 5 extractions were completed to maximize overall recovery and to determine whether a complete PL recovery could be obtained. The highest PL recovery in the first extractions was seen using the $90 \%$ ethanol at $80^{\circ} \mathrm{C}$ treatment. In this treatment, $84.2 \%$ of the total PL was recovered, but the PL content in this lipid fraction was only $33.9 \%$, which is similar to the WPPC PL content of $29.1 \%$. The PL content of the 4 remaining extractions was less than $16.3 \%$. Even though the 5 extractions in this treatment resulted in a total PL recovery of $100.8 \%$, a higher amount of neutral lipids was also recovered, leading to an overall lipid fraction with a lower PL content. Similar recoveries were observed with the $90 \%$ ethanol at $70^{\circ} \mathrm{C}$ treatment.

The highest PL content lipid fraction was obtained during the $70 \%$ ethanol at $70^{\circ} \mathrm{C}$ treatment. The fifth extraction of this treatment resulted in a lipid fraction with a PL content of $65.6 \%$, but only $2.6 \%$ of total PL was recovered during this extraction. The PL content in the extracted lipid fraction increased relatively as less total lipid was recovered. Ethanol at this temperature and concentration also seemed to have a higher affinity for PL during the later stages of these extractions. For the combined 5-fraction product, the $70 \%$ and $70^{\circ} \mathrm{C}$ condition also gave a lipid fraction that contained 


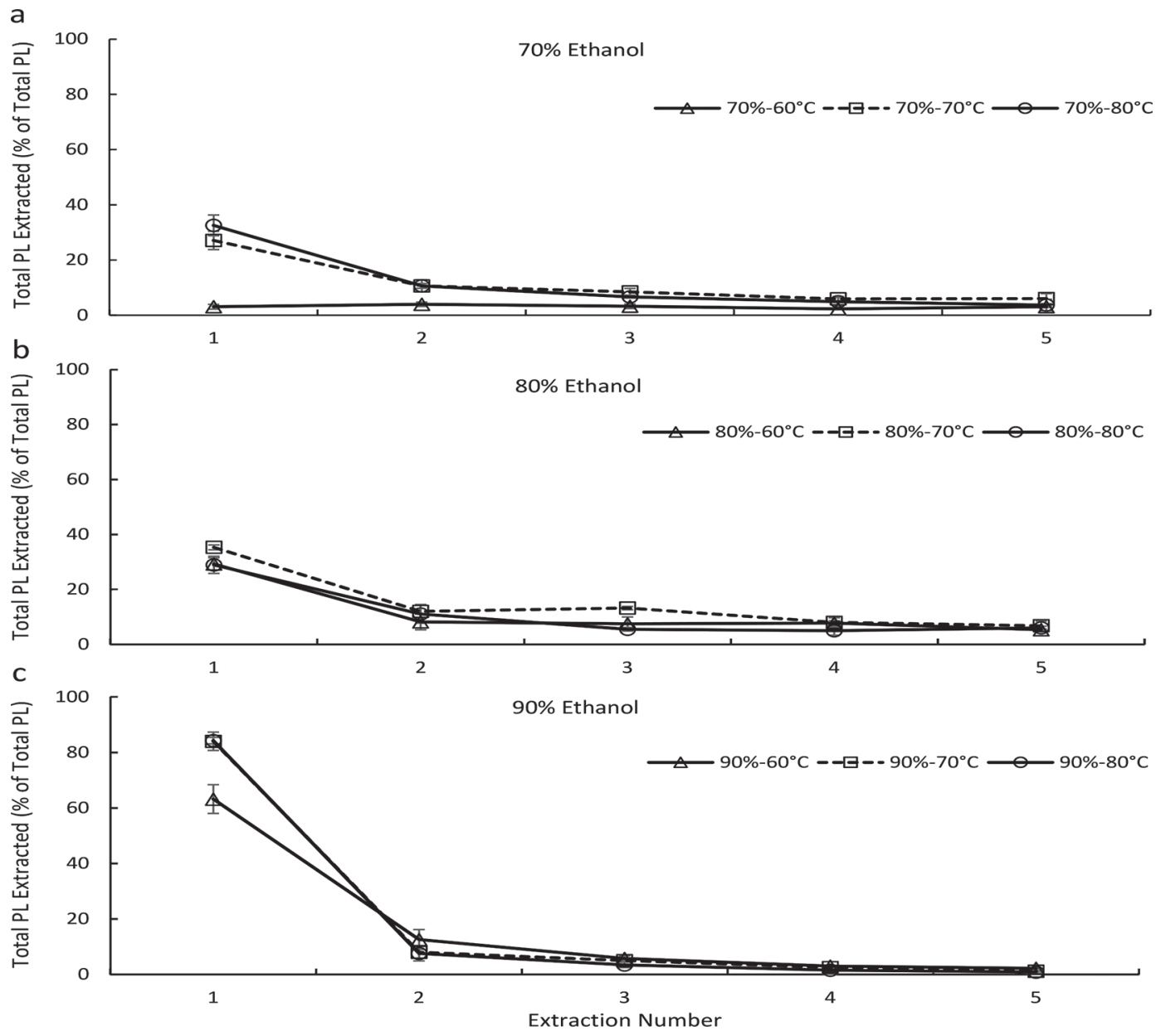

Figure 5. Effect of extraction number, temperature, and ethanol concentration on total phospholipid (PL) recovery relative to total PL recovered. Error bars are relative average SD from the mean.

$45.8 \% \mathrm{PL}$, and it represented 40.7 and $58.1 \%$ of total lipid and PL in the original WPPC, respectively, as discussed previously.

Overall, the extraction method is capable of producing a lipid fraction with high PL content, but total PL recovery also needs to be considered to make this a feasible method for industrial application. The optimal treatment should give a high PL recovery while also producing a high PL content lipid fraction. From an industry standpoint, the number of extractions could potentially be reduced to as few as 1 or 2 extractions due to these extractions being able to recover the majority of lipid. If 1 extraction is used, the $90 \%$ ethanol at $70^{\circ} \mathrm{C}$ treatment will likely lead to optimal efficiency; in the present study it resulted in a high total lipid recovery $(62.1 \%$ ) and PL content of $39.8 \%$ (Table 2). However, if a higher PL content lipid fraction is needed, ethanol concentration of $70 \%$ and $70^{\circ} \mathrm{C}$ should be selected, as such conditions produced a lipid fraction with the highest average PL content (Table 2). There is a delicate balance among all of these parameters. These results should provide an insightful direction for further industrial-scale optimization trials.

\section{Effect of Temperature and Ethanol Concentration on PL Class Composition of the Products}

The PL class composition of each extracted lipid was determined to evaluate the effect of temperature and ethanol concentration (Table 2). The PL classes SM and PS are of specific interest due to their health benefits, and the enrichment of these PL during the extraction process is desired. Table 2 shows that the $70 \%$ ethanol at $60^{\circ} \mathrm{C}$ treatment resulted in a lipid fraction with the highest SM content (17.5-23.8\%). This is a significantly higher SM enrichment when compared with the 70 and $80^{\circ} \mathrm{C}$ treatments $(P<0.05)$. When the temperature was $60^{\circ} \mathrm{C}$, a more aqueous alcohol solvent system had a higher affinity toward SM compared with other classes of PL. Compared with the starting SM 
Table 2. Total phospholipid (PL) content of each extraction and combined extractions and PL class composition ${ }^{1}$

\begin{tabular}{|c|c|c|c|c|c|c|}
\hline Treatment $^{2}$ and extraction no. & \multicolumn{5}{|c|}{ Relative composition of $\mathrm{PL}^{3}$ ( $\%$ of total PL) } & $\begin{array}{c}\text { Total PL } \\
\text { (\% of total lipid) }\end{array}$ \\
\hline \multicolumn{7}{|l|}{$70 \%$ at $60^{\circ} \mathrm{C}$} \\
\hline 2 & 18.9 & 33.8 & 5.9 & 5.6 & 35.8 & 50.2 \\
\hline 3 & 21.8 & 30.5 & 6.0 & 6.9 & 34.8 & 43.9 \\
\hline 4 & 23.8 & 29.0 & 5.7 & 7.3 & 34.2 & 39.3 \\
\hline 5 & 22.2 & 29.6 & 7.6 & 7.4 & 33.2 & 44.0 \\
\hline 1 & 11.5 & 38.7 & 4.8 & 8.7 & 36.3 & 36.8 \\
\hline 2 & 8.3 & 43.5 & 8.7 & 8.0 & 31.5 & 57.6 \\
\hline 3 & 9.4 & 43.1 & 8.6 & 9.1 & 29.8 & 63.5 \\
\hline 4 & 8.6 & 41.5 & 12.2 & 8.9 & 28.8 & 61.6 \\
\hline 5 & 9.5 & 42.3 & 11.8 & 9.0 & 27.4 & 65.6 \\
\hline Combined & 10.5 & 40.2 & 6.7 & 8.7 & 33.9 & 45.8 \\
\hline \multicolumn{7}{|l|}{$70 \%$ at $80^{\circ} \mathrm{C}$} \\
\hline 1 & 8.3 & 42.6 & 8.1 & 6.9 & 34.1 & 39.8 \\
\hline \multicolumn{7}{|l|}{$80 \%$ at $60^{\circ} \mathrm{C}$} \\
\hline 1 & 13.0 & 37.9 & 4.5 & 6.4 & 38.2 & 42.9 \\
\hline 2 & 15.0 & 38.0 & 5.7 & 6.6 & 34.7 & 42.1 \\
\hline 3 & 11.6 & 40.8 & 7.8 & 7.7 & 32.1 & 48.7 \\
\hline 4 & 15.9 & 38.4 & 8.3 & 8.1 & 29.3 & 48.3 \\
\hline 5 & 12.4 & 41.3 & 10.4 & 8.5 & 27.4 & 42.5 \\
\hline Combined & 13.4 & 38.6 & 6.1 & 7.0 & 34.9 & 44.1 \\
\hline \multicolumn{7}{|l|}{$80 \%$ at $70^{\circ} \mathrm{C}$} \\
\hline 1 & 9.4 & 43.8 & 3.5 & 6.8 & 36.5 & 37.7 \\
\hline 2 & 8.4 & 46.1 & 6.6 & 6.7 & 32.2 & 41.4 \\
\hline 3 & 12.7 & 43.3 & 5.9 & 6.9 & 31.2 & 45.7 \\
\hline 4 & 10.1 & 45.4 & 7.1 & 6.4 & 31.0 & 37.8 \\
\hline 5 & 15.5 & 44.0 & 12.2 & 9.5 & 18.8 & 36.3 \\
\hline Combined & 10.4 & 44.3 & 5.6 & 7.0 & 32.7 & 39.3 \\
\hline \multicolumn{7}{|l|}{$80 \%$ at $80^{\circ} \mathrm{C}$} \\
\hline 4 & 15.7 & 38.9 & 13.6 & 11.4 & 20.4 & 16.5 \\
\hline 5 & 11.6 & 42.4 & 16.2 & 14.5 & 15.3 & 12.7 \\
\hline Combined & 14.3 & 39.0 & 8.6 & 7.9 & 30.1 & 30.5 \\
\hline \multicolumn{7}{|l|}{$90 \%$ at $70^{\circ} \mathrm{C}$} \\
\hline 1 & 9.6 & 43.8 & 7.4 & 6.9 & 32.3 & 39.8 \\
\hline 2 & 14.0 & 43.5 & 7.9 & 7.3 & 27.3 & 18.4 \\
\hline 3 & 15.0 & 39.0 & 12.8 & 10.6 & 22.6 & 16.2 \\
\hline 4 & 13.7 & 34.2 & 21.4 & 15.2 & 15.5 & 12.7 \\
\hline 5 & 16.2 & 45.1 & 0.0 & 21.3 & 17.4 & 8.7 \\
\hline Combined & 11.3 & 42.8 & 8.5 & 8.5 & 29.0 & 31.6 \\
\hline \multicolumn{7}{|l|}{$90 \%$ at $80^{\circ} \mathrm{C}$} \\
\hline 1 & 7.7 & 46.1 & 6.6 & 7.3 & 32.3 & 33.9 \\
\hline 2 & 14.7 & 41.9 & 9.1 & 8.7 & 25.6 & 16.3 \\
\hline 3 & 14.1 & 36.7 & 13.9 & 13.2 & 22.1 & 12.7 \\
\hline 4 & 17.1 & 43.6 & 0.0 & 19.8 & 19.5 & 10.1 \\
\hline 5 & 20.6 & 39.7 & 0.0 & 12.3 & 27.4 & 8.3 \\
\hline Combined & 9.9 & 44.5 & 7.0 & 8.6 & 29.9 & 28.2 \\
\hline WPPC Folch extraction & 7.9 & 47.8 & 8.2 & 5.1 & 31.0 & 29.1 \\
\hline
\end{tabular}

${ }^{1}$ The relative average deviation from the mean for all values ranged from 0.0 to 6.9 .

${ }^{2}$ For the first extraction, the ethanol solvent concentration was $100 \%$ so that the concentration of the mixture would be 70,80 , or $90 \%$ after whey protein phospholipid concentrate (WPPC) was injected (taking the moisture content of WPPC into consideration). For all subsequent extractions, prepared solvent solutions with 70,80 , and $90 \%$ ethanol were used.

${ }^{3} \mathrm{SM}=$ sphingomyelin; $\mathrm{PE}=$ phosphatidylethanolamine; $\mathrm{PS}=$ phosphatidylserine; $\mathrm{PI}=$ phosphatidylinositol; $\mathrm{PC}=$ phosphatidylcholine. 
content in WPPC, which was $7.9 \%$ of PL, an increase in SM content of about 3 times was achieved with the $70 \%$ ethanol at $60^{\circ} \mathrm{C}$ extraction. However, the total lipid and PL yield (13.6 and 15.7\%) and the PL content $(33.7 \%)$ were all very low.

Table 2 also shows that SM percentage decreased when ethanol concentration increased from 70 to $80 \%$ and 80 to $90 \%$. Although not as significant as temperature, ethanol concentration played an important role. With a lower ethanol concentration, the solvent system had a higher polarity, which favors the extraction of SM because this PL class is the most polar class found in WPPC (Christie and Han, 2010). Lower ethanol concentrations and extraction temperatures tended to produce lipid fractions with higher SM content.

Regarding PS, we observed (Table 2) that only the extraction number had a significant effect on the enrichment of PS $(P<0.05)$. There was a slight increase in PS concentration as the extraction temperature increased, but it was not statistically significant. According to Table 2, higher PS enrichment can be achieved during the later extractions. This is due to other PL classes being extracted more efficiently during the first extractions, leading to less competition for PS during the later extractions. For all ethanol concentrations and extraction temperature, PS concentration tended to increase with the extraction number. The highest overall PS recovery was achieved using the $70 \%$ ethanol at $80^{\circ} \mathrm{C}$ treatment, and PS content of the resulting lipid fraction was 1.3 times higher than the starting WPPC. Phosphatidylserine did not become as concentrated as SM during extraction, which indicates that ethanol had a higher affinity toward SM than PS. Because PS was extracted more efficiently during the later extractions, this extraction process may not be feasible to target this PL class from WPPC.

Other PL classes such as PC, PI, and PE all responded to ethanol concentration, extraction temperature, and extraction numbers differently. Lower ethanol concentration and temperature tend to result in a higher PC enrichment. Higher ethanol concentration led to higher enrichment of PI. Higher temperature promoted $\mathrm{PE}$ recovery, but ethanol concentration seemed to have little influence.

Overall, recovery from multiple-stage extraction with $90 \%$ ethanol at 70 or $80^{\circ} \mathrm{C}$ will give near-complete extraction of total lipid and PL, but the product will not have PL enrichment. Such total lipid may be fractionated further to separate the 2 lipid classes. If PL content is a primary concern, the $70 \%$ ethanol at $70^{\circ} \mathrm{C}$ will give a product with $45.8 \%$ PL but with 40.7 and $58.1 \%$ total and PL recovery from the WPPC. This incomplete lipid recovery may cause concern.

\section{CONCLUSIONS}

The modified STEP method was shown to be effective and efficient in producing dairy PL concentrate. Higher ethanol concentration and extraction temperature led to a higher total lipid recovery, whereas lower ethanol concentration solvent had a greater affinity for PL. Different classes of PL responded to ethanol concentration and extraction temperature differently. The optimum processing condition is dependent on the desired PL content and recovery yield. The highest total lipid recovery can be achieved with $90 \%$ ethanol at 70 and $80^{\circ} \mathrm{C}$, and lipid fraction with highest PL content can be obtained using $70 \%$ ethanol at $70^{\circ} \mathrm{C}$. Among the highly nutritionally valuable PL classes, SM was favored during $70 \%$ ethanol extraction at $60^{\circ} \mathrm{C}$, whereas PS enrichment required removal of other lipids first. Overall, a dairy PL concentrate comparable with the commercial lecithin product can be produced with the extraction method demonstrated in this study.

\section{ACKNOWLEDGMENTS}

This research was supported by funds from the Midwest Dairy Association (St. Paul, MN) and National Dairy Council (Rosemont, IL). We are grateful to Bongards' Creameries (Perham, MN) for providing the whey protein phospholipid concentrate for this research.

\section{REFERENCES}

Astaire, J. C., R. Ward, J. B. German, and R. Jimenez-Flores. 2003 Concentration of polar MFGM lipids from buttermilk by microfiltration and supercritical fluid extraction. J. Dairy Sci. 86:22972307.

Barry, K. M., T. G. Dinan, and P. M. Kelly. 2017. Pilot scale production of a phospholipid-enriched dairy ingredient by means of an optimized integrated process employing enzymatic hydrolysis, ultrafiltration and super-critical fluid extraction. Innov. Food Sci. Emerg. Technol. 41:301-306.

Boyd, L. C., N. C. Drye, and A. P. Hansen. 1999. Isolation and characterization of whey phospholipids. J. Dairy Sci. 82:2550-2557.

Burling, H., and G. Graverholt. 2008. Milk-A new source for bioactive phospholipids for use in food formulations. Lipid Technol. 20:229-231.

Christie, W. W., and X. Han. 2010. Lipid analysis: Isolation, separation, identification and lipidomic analysis. 4th ed. Oily Press, Bridgwater, UK.

Contarini, G., and M. Povolo. 2013. Phospholipids in milk fat: Composition, biological and technological significance, and analytical strategies. Int. J. Mol. Sci. 14:2808-2831.

Costa, M. R., X. E. Elias-Argote, and R. Jiménez- Flores. 2010. Use of ultrafiltration and supercritical fluid extraction to obtain a whey buttermilk powder enriched in milk fat globule membrane phospholipids. Int. Dairy J. 20:598-602.

Dewettinck, K., R. Rombaut, N. Thienpont, T. T. Le, K. Messens, and J. van Camp. 2008. Nutritional and technological aspects of milk fat globule membrane material. Int. Dairy J. 18:436-457.

Donato, P., F. Cacciola, F. Cichello, M. Russo, P. Dugo, and L. Mondello. 2011. Determination of phospholipids in milk samples by means of hydrophilic interaction liquid coupled to evaporative 
light scattering and mass spectrometry detection. J. Chromatogr. A 1218:6476-6482.

Folch, J., M. Lees, and G. H. Stanley. 1957. A simple method for the isolation and purification of total lipids from animal tissues. J. Biol. Chem. 226:497-509.

Fong, B., L. Ma, and C. Norris. 2013. Analysis of phospholipids in infant formulas using high performance liquid chromatographytandem mass spectrometry. J. Agric. Food Chem. 61:858-865.

Fong, B. Y., C. S. Norris, and A. K. H. MacGibbon. 2007. Protein and lipid composition of bovine milk-fat-globule membrane. Int. Dairy J. $17: 275-288$

Le, T. T., J. Miocinovic, J. Van Camp, B. Devreese, K. Struijs, T. Van de Wiele, and K. Dewettinck. 2011. Isolation and applications of milk fat globule membrane material: Isolation from buttermilk and butter serum. Commun. Agric. Appl. Biol. Sci. 76:111-114.

Levin, M. A., K. J. Burrington, and R. W. Hartel. 2016. Composition and functionality of whey protein phospholipid concentrate and delactosed permeate. J. Dairy Sci. 99:6937-6947.

Li, B., Z. Linghu, S. J. Smith, and J. K. Amamcharla. 2016. Extraction of phospholipids from procream using supercritical carbon dioxide and ethanol as a modifier. J. Anim. Sci. 94:256.

Nejrup, R. G., T. R. Licht, and L. Hellgren. 2017. Fatty acid composition and phospholipid types used in infant formulas modifies the establishment of human gut bacteria in germ-free mice. Sci. Rep. $7: 3975$.

Pepeu, G., I. M. Pepeu, and L. Amanducci. 1996. A review of phosphatidylserine pharmacological and clinical effects. Is phosphatidylserine a drug for the ageing brain? Pharmacol. Res. 33:73-80.

Rodríguez-Alcalá, L. M., and J. Fontecha. 2010. Major lipid classes separation of buttermilk, and cows, goats and ewes milk by high performance liquid chromatography with an evaporative light scattering detector focused on the phospholipid fraction. J. Chromatogr. A 1217:3063-3066.

Rombaut, R., J. V. Camp, and K. Dewettinck. 2006. Phospho- and sphingolipid distribution during processing of milk, butter and whey. Int. J. Food Sci. Technol. 41:435-443.

Rombaut, R., V. Dejonckheere, and K. Dewettinck. 2007. Filtration of milk fat globule membrane fragments from acid buttermilk cheese whey. J. Dairy Sci. 90:1662-1673.

Rombaut, R., and K. Dewettinck. 2006. Properties, analysis and purification of milk polar lipids. Int. Dairy J. 16:1362-1373.

Sala-Vila, A., A. I. Castellote, M. Rodriguez-Palmero, C. Campoy, and C. Lopez-Sabater. 2005. Lipid composition in human breast milk from Granada (Spain): Changes during lactation. Nutrition 21:467-473.

Spence, A. J., R. Jimenez-Flores, M. Qian, and L. Goddik. 2009. Phospholipids enrichment in sweet and whey cream buttermilk powders using supercritical fluid extraction. J. Dairy Sci. 92:2373-2381.

Walstra, P., J. T. M. Wouters, and T. J. Geurts. 2006. Dairy Science and Technology. 2nd ed. Taylor and Francis, Boca Raton, FL.

Wang, H., L. Yao, S. L. Lee, and T. Wang. 2016. Extraction of phospholipids from egg yolk flakes using aqueous alcohols. J. Am. Oil Chem. Soc. 94:309-314.

Wang, H., L. Yao, S. L. Lee, and T. Wang. 2017. Simultaneous texturization and extraction of phospholipids from liquid egg yolk using renewable solvents. Eur. J. Lipid Sci. Technol. 119:1500523.

Wang, H., L. Yao, and T. Wang. 2014. Extraction of phospholipids from structured dry egg yolk. J. Am. Oil Chem. Soc. 91:513-520. 